\title{
TECNOLOGIA E DESIGN: conceito de dispositivo portátil para monitoramento de oxigenação arterial
}

\section{TECHNOLOGY AND DESIGN: concept of portable device for monitoring blood oxygenation}

\author{
Letícia Cristina Pereira da Silva ${ }^{1}$, Tecg. \\ Ana Cristina Maurício Ferreira², MsC. \\ Paulo Sérgio Pereira Pinto ${ }^{3}$, Esp. \\ Adriana Sierra Assencio Almeida Barbosa ${ }^{4}, \mathrm{Dr}^{\mathrm{a}}$. \\ (1) Faculdade de Tecnologia de Bauru (FATEC) \\ e-mail: lelepereira19942015@gmail.com
}
(2) Universidade Estadual Paulista (UNESP), PPGDesign-FAAC
e-mail:anacrfatec@gmail.com

(3) Faculdade de Tecnologia de Bauru (FATEC)

e-mail: paulospp2000@gmail.com

(4) Faculdade de Tecnologia de Bauru (FATEC)

e-mail: drisierra@hotmail.com

Palavras chave: Oxigenação arterial, Oxímetro de pulso, Arduino, Raspberry PI.

O transporte pela corrente sanguínea e a troca gasosa pulmonar do oxigênio e do dióxido de carbono são essenciais para manutenção da homeostasia, sendo o oxímetro de pulso um excelente dispositivo que fornece rapidamente e de forma não invasiva a concentração de oxigênio no sangue arterial. Este trabalho teve o objetivo de desenvolver um dispositivo que possibilita o armazenamento e disponibilização das informações geradas pelo oxímetro de pulso à equipe médica responsável pelo acompanhamento do paciente. A proposta apresentada deverá propiciar ao paciente, assim como à sociedade em geral, rapidez e confiabilidade no acompanhamento médico, contribuindo para uma melhor terapêutica.

\section{Keywords: Blood Oxygenation. Pulse oximeter, Arduino, Raspberry PI.}

Carriage through the bloodstream and pulmonary gas exchange of oxygen and carbon dioxide are essential for the maintenance of homeostasis, and the pulse oximeter is an excellent device that rapidly and noninvasively supplies the oxygen concentration in the arterial blood. This work aimed to develop a device that allows the storage and availability of information generated by the pulse oximeter to the medical team responsible for patient follow - up. The proposal presented should provide the patient, as well as society in general, with speed and reliability in medical follow-up, contributing to a better therapeutics. 


\section{$16^{\circ}$ \\ ERGODESIGN USIHC CINAHPA}

$16^{\circ}$ Ergodesign - Congresso Internacional de Ergonomia e Usabilidade de Interfaces Humano Tecnológica: Produto, Informações Ambientes Construídos e Transporte

$16^{\circ}$ USIHC - Congresso Internacional de Ergonomia e Usabilidade de Interfaces Humano Computador

CINAHPA | 2017 - Congresso Internacional de Ambientes Hipermídia para Aprendizagem.

\section{Introdução}

Não se pode entender a aplicação da tecnologia no design como o simples uso de ferramentas ou softwares. A palavra tecnologia, dentre as diversas interpretações, é o estudo dos conhecimentos da atividade humana, como as artes e ciências. Comumente é utilizada para destacar características técnicas (ou eletrônicas) de produtos.

Conforme abordado por Cresto (2009), a tecnologia não é simplesmente a materialização de uma proposta por meio de instrumentos, mas um saber que tem se desenvolvido ao longo da história humana, devendo ser discutida em sua dimensão cultural, sua inserção na sociedade e como produto do conhecimento humano.

O uso da tecnologia no desenvolvimento de processos, produtos ou sistemas de fabricação acaba por fornecer informações sobre uma sociedade, ou seja, seus conhecimentos dentro de um determinado contexto histórico. Neste sentido, a aplicação dos conhecimentos tecnológicos aliados ao design, são voltados ao melhor atendimento das necessidades de determinado público, facilitando tarefas do cotidiano.

Equipamentos médicos hospitalares tem grande importância na manutenção da saúde dos indivíduos. Soluções que envolvam design e tecnologia são propostas que tendem a facilitar o acompanhamento da saúde de pacientes.

Pacientes debilitados ou com certas doenças crônicas necessitam de acompanhamento diário e monitoramento da oxigenação arterial. As aferições são realizadas com o oxímetro de pulso, que é um dispositivo composto por um cabo que tem um sensor de saturação de oxigênio no sangue ( $\mathrm{SpO} 2)$. Os valores aferidos, comumente, são anotados de forma manual no prontuário do paciente.

Este trabalho teve por objetivo apresentar um projeto conceitual de um dispositivo portátil que possa facilitar a monitoração da oxigenação arterial do paciente e o acompanhamento pelo médico responsável. $\mathrm{O}$ mesmo é composto de um oxímetro de pulso acoplado a uma placa de Arduino ligada a um servidor web Raspberry Pi. O profissional da área da saúde irá acompanhar as medições obtidas do paciente por meio de seu smartphone ou outro dispositivo eletrônico, como tablets, notebooks, computadores.

Pretende-se, com esta proposta, otimizar o acompanhamento de pacientes, com um projeto de baixo custo, atendendo assim hospitais de pequeno porte, clínicas e até mesmo pessoas que fazem tratamentos em suas residências e necessitam de cuidados especiais. $\mathrm{O}$ acesso a este dispositivo proposto sugere que o profissional da saúde possa ter controle da oxigenação arterial do paciente, facilitando o seu trabalho e o suporte ao paciente, que terá cuidados mais eficientes, cuidando de patologias já instaladas e prevenindo complicações, contribuindo para o bem-estar da sociedade.

\section{Fundamentos teóricos}

\subsection{Fundamentos fisiológicos: oxigenação arterial}

O oxigênio $(\mathrm{O} 2)$ é uma das principais substâncias necessárias para as reações químicas no interior das células, é muito importante que o corpo disponha de mecanismo especial de controle para manter uma concentração de oxigênio constante e quase invariável (GUYTON; HALL, 2011).

A concentração de oxigênio necessária para o organismo requer o funcionamento coordenado dos sistemas circulatório e respiratório, estimulando a troca gasosa nos pulmões, que ao mesmo tempo que o sangue capta oxigênio nos alvéolos, $o$ dióxido de carbono $\left(\mathrm{CO}_{2}\right)$ está sendo liberado do sangue para os alvéolos, e o movimento respiratório do ar, para dentro e para fora dos alvéolos, transporta esse gás para atmosfera (WIDMAIER et al, 2013).

A composição do ar inspirado e a eficácia da ventilação alveolar afetam as trocas gasosas e a pressão do oxigênio $\left(\mathrm{Po}_{2}\right)$ e do dióxido de carbono $\left(\mathrm{PcO}_{2}\right)$ são influenciadas pelos gradientes de
Realização:

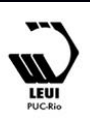




\section{$16^{\circ}$ \\ ERGODESIGN USIHC CINAHPA}

pressão parcial, pela área de superfície alveolar, pela espessura da membrana alveolar e pela distância intersticial entre os alvéolos e os capilares pulmonares (TORTORA; DERRICKSON, 2012).

$\mathrm{A} \mathrm{Po}_{2}$ alveolar e arterial normal é de aproximadamente de $100 \mathrm{mmHg}$. $\mathrm{A} \mathrm{Pco}_{2}$ arterial e alveolar normal é de cerca de $40 \mathrm{mmHg}$. $\mathrm{A} \mathrm{Po}_{2}$ venosa normal é de $40 \mathrm{mmHg}$ e a $\mathrm{PcO}_{2}$ venosa normal é de 46 mmHg (GUYTON; HALL, 2011).

O oxigênio é transportado dissolvido no plasma $(<2 \%)$ e ligado à hemoglobina (>98\%). O transporte do dióxido de carbono é realizado em $7 \%$ dissolvido no plasma, $23 \%$ ligado a hemoglobina e $70 \%$ como íon bicarbonato no plasma (GUYTON; HALL, 2012).

Um importante indicador clínico da eficácia das trocas gasosas nos pulmões é a concentração de oxigênio no sangue arterial. Um excelente dispositivo é o oxímetro de pulso, que mede rapidamente e de forma indolor os níveis de oxigênio sanguíneo através da superfície da pele, e em segundos gera uma leitura digital da saturação do oxigênio. O oxímetro funciona medindo a absorbância da luz do tecido em dois comprimentos de onda, fornecem um meio rápido e não invasivo de estimar o conteúdo arterial de oxigênio. É essencial para a homeostasia do organismo, sendo o oxímetro de pulso um excelente instrumento para controlar e prevenir sérias complicações em diversas patologias (SILVERTHORN, 2010).

\subsection{Fundamentos tecnológicos: Raspberry PI e Arduino}

O Raspberry Pi é um microcomputador OSH desenvolvido na Grã-Bretanha, de dimensões reduzidas, idealizado sob o paradigma System On a Chip com a capacidade de processamentos suficientes para executar tarefas realizadas por computadores desktop, como processamento de jogos, edição de texto e planilhas, navegação na internet, entre outros (EDWARDS, 2013). $16^{\circ}$ Ergodesign - Congresso Internacional de Ergonomia e Usabilidade de Interfaces Humano Tecnológica: Produto, Informações Ambientes Construídos e Transporte

$16^{\circ}$ USIHC - Congresso Internacional de Ergonomia e Usabilidade de Interfaces Humano Computador

CINAHPA | 2017 - Congresso Internacional de Ambientes Hipermídia para Aprendizagem.

Em 2012 foi lançado o primeiro modelo desse computador de dimensões reduzidas. Os criadores desse hardware tinham como objetivo inicial estimular o ensino da ciência da computação em escolas, buscando recuperar o interesse dos jovens pelo estudo de computação básica. A Figura 1 apresenta os conectores do Raspberry Pi.

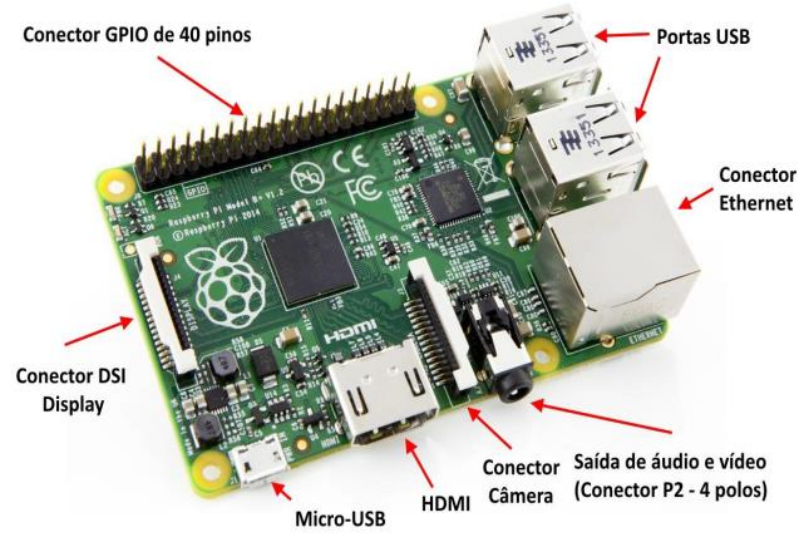

Figura 1 - Raspberry Pi conectores

Fonte: http://blog.filipeflop.com/embarcados/tutorialraspberry-pi-linux.html

O Raspberry Pi funciona como um computador, portanto é necessário ser instalado um Sistema Operacional (SO), como Linux ou Windows (RAULINO, 2013).

Para interagir com o Raspberry Pi necessita-se de monitor com entrada HDMI ou televisor com entrada RCA, mouse, teclado (o mouse é de certa forma opcional, mas facilita a interação) e para ter acesso à internet tem duas opções: cabo internet ligado a um router ou PC e Wi-fi, através de um módulo Wi-fi USB (CURVELLO, 2015).

O Raspberry Pi pode ser utilizado praticamente em todas as situações em que um computador tradicional pode ser usado e seu sistema é baseado em Linux, com ele pode-se criar servidores de aplicação, bancos de dados, arquivos e muito mais. Esta plataforma também possui um sistema de gerenciamento gráfico que permite instalar e executar aplicativos como planilha eletrônica, navegadores de internet e browser (LORENCENA et al, 2016).
Realização:
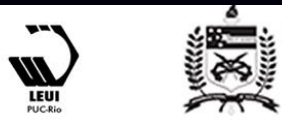


\section{$16^{\circ}$ \\ ERGODESIGN USIHC CINAHPA}

O Arduino é uma placa de prototipação opensource baseado em um microcontrolador muito versátil que permite o controle de vários dispositivos, e por essa características é muito utilizado em aplicações de instrumentação embarcada e robótica (SARIK; KYMISSIS, 2010).

É possível inserir novas funcionalidades à placa Arduino conectando placas adicionais chamadas Shields. Estas podem ser ligadas sobre a placa de circuito impresso do Arduino com a finalidade de se expandir sua capacidade (TAVARES; BRANDÃO, 2013).

De acordo com a página oficial do Arduino, a versão UNO possui 14 pinos digitais de entrada/saída - dos quais 6 podem ser destinados como saídas PWM (Modulação por Largura de Pulso), 6 são entradas analógicas, uma cristal oscilador de $16 \mathrm{MHz}$, uma conexão USB, uma tomada de força, um cabeçalho ICSP (InCircuit System Programming) e um botão de reset (MOREIRA, et al. 2013).

Arduino é baseado em um microcontrolador (ATMega) e dessa forma é logicamente programável, ou seja, é possível a criação de programas, utilizando uma linguagem própria baseada em $\mathrm{C} / \mathrm{C}++$, que, quando implementadas fazem com que o hardware execute certas ações. Dessa forma, estamos configurando a etapa de processamento (MOREIRA, et al. 2013).

O Arduino foi criado no Ano de 2005 e o Raspberry Pi em 2011, sendo lançado em 2012. A diferença entre essas duas tecnologias é que o Arduino é composto por um controlador Atmel AVR de 8 bits (com algumas versões chegando a 32 bits), suas conexões são analógicas e digitais e a entrada USB é para ligações simples e diretas aos computadores; é um microcontrolador e essa plataforma trabalha diretamente com hardware placa (SOUZA, 2015).

O Raspberry Pi, por sua vez, é uma programação de baixo custo, sendo que sua placa é do tamanho de um cartão de crédito. É um computador completo, com entradas para cabo de rede, áudio, vídeo, e cartão micros; é um multiprocessador $16^{\circ}$ Ergodesign - Congresso Internacional de Ergonomia e Usabilidade de Interfaces Humano Tecnológica: Produto, Informações Ambientes Construídos e Transporte

$16^{\circ}$ USIHC - Congresso Internacional de Ergonomia e Usabilidade de Interfaces Humano Computador

CINAHPA | 2017 - Congresso Internacional de Ambientes Hipermídia para Aprendizagem.

ideal para desenvolvimento de software com diversas linguagens de programação. O Raspberry Pi funciona em projetos de hardware sendo somente necessário utilizar os componentes e a voltagem correta para não danificar a placa (SOUZA, 2015).

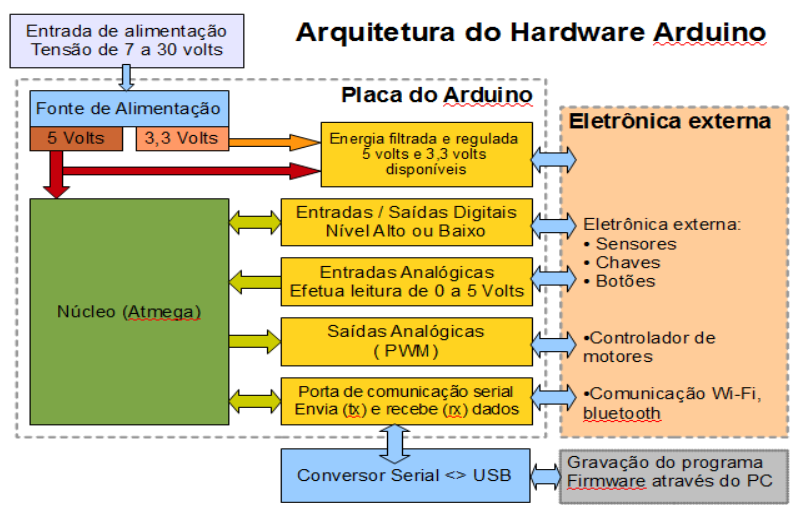

Figura 2 - Arquitetura do hardware Arduino Fonte: http://www.robotizando.com.br/ curso_arduino_hardware_pg1.php

\section{Materiais}

A plataforma Raspberry Pi necessita da utilização de um Sistema Operacional, podendo ser o Windows ou Linux. Foi escolhido o Linux, por ser um sistema de código aberto e não tem a necessidade de se adquirir a licença, como ocorre com o Windows. Há variadas distribuições do SO Linux que podem ser instaladas no Raspberry Pi. Para utilização neste projeto foi escolhido o raspian que é um Linux desenvolvido para sistema embarcado devido a sua facilidade de utilização.

Os materiais utilizados no desenvolvimento do dispositivo eletrônico de monitoramento da oxigenação são: um oxímetro, uma placa do Arduino e uma placa do Raspberry:

a) Oxímetro de pulso da marca Oxy Control Geratherm, para medir quanto de oxigênio o sangue está transportando;

b) Arduino Nano módulo programável;

c) Placa Raspeberry Pi, que será ligado ao Arduino. 


\section{$16^{\circ}$ \\ ERGODESIGN USIHC CINAHPA}

\section{Resultados}

\subsection{Características Funcionais do Equipamento}

Os parâmetros recebidos pelo oxímetro são enviados para o Arduino que irá transformar os valores elétricos coletados em dados e, por via bluetooth, estes dados serão transmitidos ao Raspberry Pi, onde estas informações serão armazenadas e disponibilizadas, possibilitando a visualização via internet pelo profissional da área médica. O diagrama disposto na Figura 6, mostra o funcionamento do dispositivo proposto. Também, mostra que os procedimentos ocorrerão em um bloco de monitoramento.

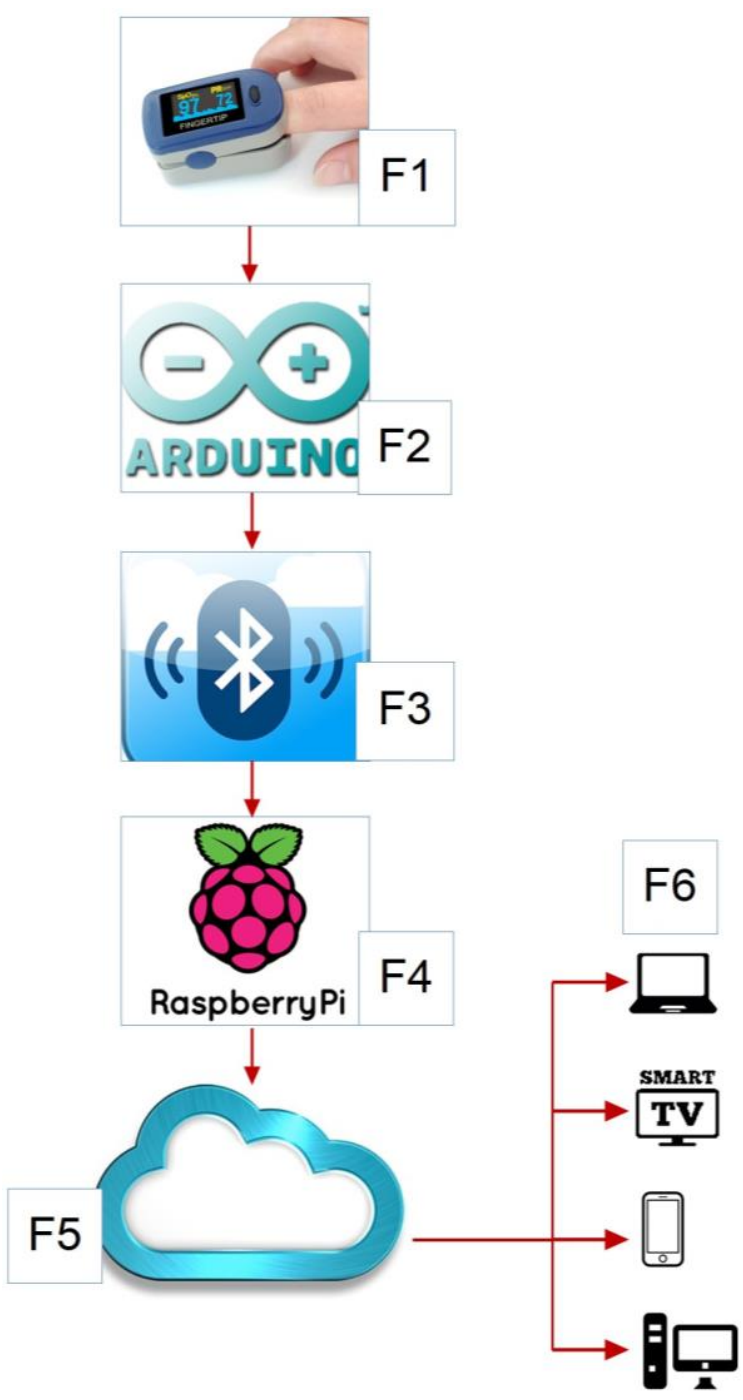

Figura 6 - Diagrama funcional do dispositivo proposto $16^{\circ}$ Ergodesign - Congresso Internacional de Ergonomia e Usabilidade de Interfaces Humano Tecnológica: Produto, Informações Ambientes Construídos e Transporte

$16^{\circ}$ USIHC - Congresso Internacional de Ergonomia e Usabilidade de Interfaces Humano Computador

CINAHPA | 2017 - Congresso Internacional de Ambientes Hipermídia para Aprendizagem.

As funções (F1 a F6) seguem conforme descrição do Quadro 1.

Quadro 1 - Funções do sistema

\begin{tabular}{|c|c|}
\hline FUNÇÃO & DESCRIÇÃO \\
\hline F1 & $\begin{array}{l}\text { Os dados são coletados do paciente } \\
\text { através do oxímetro em forma de sinais } \\
\text { elétricos. }\end{array}$ \\
\hline F2 & $\begin{array}{l}\text { Os dados são transformados em } \\
\text { informações pelo Arduino. }\end{array}$ \\
\hline F3 & $\begin{array}{l}\text { As informações são transmitidas via } \\
\text { bluetooth. }\end{array}$ \\
\hline F4 & $\begin{array}{l}\text { O Arduino, por intermédio do bluetooth } \\
\text { conecta-se ao módulo de monitoramento } \\
\text { do paciente com o Raspberry Pi. }\end{array}$ \\
\hline F5 & $\begin{array}{l}\text { Após a transmissão, as informações são } \\
\text { disponibilizadas na internet. }\end{array}$ \\
\hline F6 & $\begin{array}{l}\text { Estando disponibilizado na internet, as } \\
\text { informações podem ser acessadas } \\
\text { remotamente pelos profissionais da } \\
\text { saúde, por meio de smartphone, smartTV, } \\
\text { notebook, tablete ou computados } \\
\text { desktops. }\end{array}$ \\
\hline
\end{tabular}

\section{Conclusão}

O objetivo deste trabalho foi desenvolver o projeto conceitual de um dispositivo portátil para auxílio no monitoramento da oxigenação arterial do paciente e o acompanhamento pela equipe médica responsável. O desenvolvimento teve embasamento na relação entre design e tecnologia. $\mathrm{O}$ design aplicado no atendimento das necessidades dos indivíduos e da sociedade e a tecnologia na busca por soluções que facilitam a realização de tarefas. O dispositivo proposto deve conferir ao profissional da área da saúde agilidade no monitoramento remoto do paciente $\mathrm{e}$, ao paciente, segurança e confiabilidade dos dados aferidos, assim como a manutenção de sua saúde e precaução contra outras morbidades. 


\section{$16^{\circ}$ \\ ERGODESIGN USIHC CINAHPA}

\section{Bibliografia}

CRESTO, L. J. A re-significação da relação entre design e tecnologia na obra dos Irmãos Campana. 2009. Dissertação de Mestrado. Universidade Tecnológica Federal do Paraná

CURVELLO, A. Sistema web com Raspberry Pi, Arduino, USB, Lighttpd e PHP. Embarcados. 2015. Disponível em: http://www.embarcados.com.br/sistema-webcomraspberry-pi-e-arduino/?utm_content =buffera6e37\&utm_medium=social\&utm_source= facebook.com\& utm_campaign=buffer. Acesso em 01 jun 2016.

EDWARDS, C. Not-so-humble raspberry pi gets big ideas. Engineering Technology, v. 8, n. 3, p. 30-33, 2013.

GUYTON, A.C.; HALL, J.E. Tratado de Fisiologia Médica. 12 ed. Rio de Janeiro: Guanabara Koogan, 2011.

GUYTON, A.C.; HALL, J. E. Fundamentos de Fisiologia Médica. 12 ed. Rio de Janeiro: Guanabara Koogan, 2012.

LORENCENA, M.; SILVA, W.; GALON, H. E.; BRITO, R. C. Raspberry PI: Plataforma mobile para desenvolvimento Java. Devmedia. 2016. Disponível em http://www.devmedia. com.br/raspberry-pi-plataforma-mobile-paradesenvolvimento-java/30858. Acesso em 02 mai 2016.

MOREIRA, A. S.; PORTELA, A. M.; SILVA, R. Uso da plataforma arduino no desenvolvimento de soluções tecnológicas para pesquisas de dados atmosféricos na amazônia. Revista Perspectiva Amazônica. Ano 3, n. 5, p. 119-126, 2013.

\section{RAULINO, M. F. Raspberry Pi e RFID no}

Monitoramento de Atividades de Natação. 2013. 43 f. Monografia (Especialização) - Curso de Tecnologia em Sistemas e Telecomunicações, Instituto Federal de Educação, Ciência e Tecnologia de Santa Catarina, São Jose, 2013. $16^{\circ}$ Ergodesign - Congresso Internacional de Ergonomia e Usabilidade de Interfaces Humano Tecnológica: Produto, Informações Ambientes Construídos e Transporte

$16^{\circ}$ USIHC - Congresso Internacional de Ergonomia e Usabilidade de Interfaces Humano Computador

CINAHPA | 2017 - Congresso Internacional de Ambientes Hipermídia para Aprendizagem.
SARIK, J.; KYMISSIS, I. Lab kits using the Arduino prototyping platform. In: Frontiers in Education Conference (FIE), 2010 IEEE. IEEE, 2010. p. T3C-1-T3C-5.

SILVERTHORN, D. U. Fisiologia Humana: uma abordagem integrada. 5 ed. Porto Alegre: Artmed, 2010 .

TORTORA, G. J.; DERRICKSON, B. Corpo Humano: Fundamentos de Anatomia e Fisiologia. 8 ed. Porto Alegre: Artmed, 2012.

WIDMAIER, E.P.; RAFF，H.; STRANG，K.T. Fisiologia Humana: os mecanismos das funções corporais. 12 ed. Rio de Janeiro: Guanabara Koogan, 2013.
Realização:
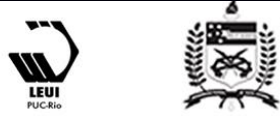